\title{
La Penitencia y sus formas
}

\section{Examen de su evolución histórica (Continuación)}

\section{b. Los escritos de Tertuliano católico.}

La favorable acogida prestada al pensamiento de Hermas fructifica en las instituciones o institución penitencial, sobre la que Tertuliano habla con mayor seguridad que Hermas. Sin duda influye la mayor formación intelectual de Tertuliano, pero su reflexión se apoya en el desarrollo conseguido por las nacientes formas penitenciales. En el De poenitentia se reflejan las diversas instituciones católicas de la iglesia de Cartago, entre las que nos interesa de una forma especial la del catecumenado, a cuyos pertenecientes Tertuliano llama caudientess).

Se ha querido ver el mérito fundamental de Tertuliano en las descripciones que hace del ritual de la primitiva penitencia. Es cierto que transmite valiosas referencias no contenidas en escritores anteriores al describir con cierto detalle la penitencia como ejercicio público: el pecador dormirá en ceniza y revestido de saco se postrará a los pies de los presbíteros, ante los «santos», y pedirá perdón a todos los hermanos y sus oraciones ante Dios. Estos rasgos difusos no han pasado desapercibidos a los fieles de la iglesia de Africa y Tertuliano, libre de la preocupación de temas más fundamentales, se detiene en su descripción detallada, aún consciente de que la dureza de los mismos alejaría a muchos de la práctica de la penitencia.

Pero de mayor valor es la firmeza con que Tertuliano defiende que esta penitencia segunda, interna - sin olvidar las discusiones sobre el significado de "poenitentia secunda» en Tertuliano- debe ex-

* Cfr. Estudio Agustiniano 7 (1972) 37-70 
teriorizarse mediante un acto externo por el cual el penitente confiesa su pecado ante Dios, no como pensando que Dios lo ignora, sino en cuanto que esta confesión engendra el arrepentimiento y éste, la congratulación con Dios. Igualmente es importante su insistencia en que esta penitencia ha de ser laboriosa, de manera que no puede ser dejada al sencillo arbitrio del particular. La intervención de una autoridad distinta de la conciencia individual del pecador que se arrepiente salta a la vista en la lectura de sus obras. Finalmente debemos prestar atención a la seguridad con que Tertuliano afirma la existencia del $p o$ der de perdonar los pecados y todos los pecados sin restricción alguna, en el sentido de Hermas.

Este exponía su pensamiento de una manera difusa, como temiendo oponerse a la conciencia que en aquellos momentos imperaba en su iglesia. Para Tertuliano ha desaparecido ya toda prevención. Renuncia a la exposición alegórica y expone su pensamiento con rasgos claros, decididos y precisos. Convierte en ley y derecho ordinarios de todo cristiano que ha pecado, lo que Hermas describía como (cexcepcional» y (jubileo». Y hasta apoya su pensamiento en pruebas bíblicas: la Iglesia tiene poder, y puede hacer efectivo su poder de perdonar todos los pecados ${ }^{79}$.

\section{c. El llamado Edicto de Calixto.}

Otro de los documentos importantes de la historia penitencial de

79. Tertuliano, De poenitentia VII, 14, PL 1, 1240-1242; VIII, 9, PL 1 , 1242-1243; II, 3, PL 1, 1228-1231; IX, 1-3, PL 1, 1243-1244; De pudicitia III, 5, PL 2, 983-985; V, 14, PL 2, 987-989; XIII, 7, PL 2, 1003-1005. Comentarios orientadores sobre este punto pueden encontrarse juntamente conuna amplia bibliografía especializada en : P. BATIFFor, Etudes d'histoire positive. La discipline de l'arcane. Les origines de la pénitence, Paris 1920, 10, 5-7, 74-75; B. Poschmann, Pénitence et onction des malades, París 1967, 47; 48; C. VoGEL, Le pécheur et la pénitence dans l'Eglise Ancienne, París 1966, 20. Tertuliano, De poenitentia IX, 5, PL, 1, 1234-1236: "Plerosque hoc opus ut publicationem sui, aut suffugere aut de die in diem praesumo". Es una preocupación que se repite en casi todos los pastores de almas de estos siglos y que llega a justificar, en su conciencia pastoral, procederes distintos de la penitencia oficial. Sería largo amontonar aqui todas las citas. Unicamente llamo la atención sobre $\mathbf{S}$. Cesareo de Arlés con su creación del "agere poenitentiam" como opuesto al "accipere poenitentlam".

Tampoco he querido pararme en la discusión sobre existencia de los pecados remisibles según Tertuliano, ya que el punto de partida de este artículo lo constituye la hipótesis de la no existencla de dichos pecados en la primitiva Iglesia. Se trata de una hipótesis fundamentada en ciertas pruebas como puede estarlo la hlpótesis contraria. 
la primitiva Iglesia es un edicto de cierto obispo influyente en la Iglesia de los primeros siglos. Los estudiosos han elaborado varias hipótesis sobre el autor del mismo. Hoy se ha descartado ya la primera hipótesis que se lo atribuía al Papa Ceferino. Una segunda hipótesis considera que su autor fue el Papa Calixto, en cuyo caso el contenido del Edicto sería atacado por dos contrarios pertenecientes a las iglesias más influyentes de los primeros siglos: Tertuliano por parte de la Iglesia de Africa, e Hipólito proveniente de la Iglesia de Roma. Tal hipótesis dificulta considerablemente la interpretación del contenido del Decreto, ya que al no conocerse directamente su contenido, es necesario deducirlo de los ataques que le dirigen tanto Tertuliano como Hipólito. Y resulta que mientras Tertuliano presenta a Calixto como conservador, Hipólito le califica de innovador. Y sin embargo esta hipótesis gozó de tal aceptación que los historiadores han dedicado profundos y complicados estudios tendentes a completar y armonizar las afirmaciones de Tertuliano con las de Hipólito.

Actualmente van ganando terreno los nuevos estudios orientados a probar que el Edicto de Calixto se debe a un obispo de Africa. No conceden demasiada importancia a la identificación de dicho obispo, si bien sus presunciones se centran en Agripino de Cartago ${ }^{80}$.

Acepto esta última hipótesis como punto de partida para la reflexión. Con ello no privo a la actuación del Papa Calixto de todo significado en el hacerse evolutivo de las formas penitenciales. Tendrá una influencia mayor o menor, pero será siempre un testimonio de la lucha que se mantenía en la Iglesia de Roma: la tendencia inclinada a la benignidad y la propensa a la rigidez ${ }^{82} \mathrm{Y}$ hasta podríamos dedu-

80. Uno de los autores que más se emplea en lograr la armonización es D'Ales, L'edit de Calliste, 217-218. 'También es conveniente no olvidar a B. Poschmann, o.c. 44-47; en él y sobre todo en Batiffol, Rev. Biblique 1906,339 s. puede encontrarse una apreciable bibliografía sobre el tema.

81. "Ce qui est certain, c'est que Callixte-selon Hyppolyte on ne peut en douter - aurait été de tendance bienveillante et qu'il aurait par tagé le point de vue des adversaires de Tertullien, même quand il né s'opposait pas directement à lui". "Quant à Hyppolyte, son attitude vis-â-vis de Callixte montre que le courant rigoriste se faisait sentir à Rome comme ailleurs. Il est difficile de fixer jusqu' où allait sa séverité envers les pénitents, s'il refusait le pardon des adultères, ainsi certainement qu'aux idolâtres et aux meurtriers - à linstar des evêques africains dont il a été question plus haut- ou s'il se bornait à exiger une pénitence importante, voire perpetuelle. En tout cas, le refus de la doctrine de Callixte n'exclut pas que l'Eglise réunit en elle des saints et des impies (Philosophoum. 
cir de la actuación del Papa Calixto, comparada con la práctica africana, cuál de las dos corrientes predominaba en Roma. El contenido del llamado Edicto de Calixto y la actuación del verdadero Papa Calixto poseen fuerza demostrativa sobre las pasiones obtenidas por las tendencias benigna y rigida en Roma y Cartago.

Trataría de entenderlo así: La aceptación del pensamiento de Hermas - que no ponía restricción alguna al ejercicio práctico del poder de perdonar los pecados - permite pensar que tales orientaciones misericordiosas no dejaron de aplicarse, al menos de manera absoluta, ni en Roma ni en Cartago. Ellos han debido de orientar la práctica penitencial a lo largo del tiempo que media entre la publicación del escrito de Hermas y la del Edicto de Calixto y la actuación del $\mathrm{Pa}$ pa Calixto ${ }^{82}$. Pero en esta orientación la tendencia benigna ha tenido que hacer frente a dudas y limitaciones impuestas por la corriente rígida, que no detentaba la misma fuerza en todas y cada una de las iglesias particulares. En la Iglesia de Africa la corriente benigna había logrado imponerse o, al menos, era más fuerte que la rígida. S. Cipriano atestigua con claridad la presencia de la tendencia rígida :

\footnotetext{
"Et quidem apud antecessores nostros quidam de exiscopis istis in provincia nostra dandam pacem moechis non putaverunt et in totum poenitentiae locum contra adulteria clauserunt. Non tamen a coepiscoporum suorum collegio recesserunt aut catholicae Ecclesiae unitatem vel duritiae vel censurae suae obstinatione ruperunt, ut, quia apud alios adulteris pax dabatur, qui non dabat de Ecclesia separaretur" 83 .
}

Existen, pues, obispos que niegan la reconciliación a los impúdi$\cos$ y adúlteros. No es que dudaran de que Dios les perdonara. Sencillamente les negaban, durante toda la vida, la re-incorporación a la comunidad fiel. Es de notar que, a los obispos que actuaban así, los señala como (episcopi dissidentes» y "quidam épiscopi», apartados de la práctica general de la iglesia de Africa : la admisión a la penitencia

IX, 12,22s) et qu' elle accueille les pécheurs repentants ayant expié leur faute" (B. Poschmann, o.c. 53) ; P. BATIFFol, o. c. XXIV-XXV, XIX-XX; Fititz- Martin, Histoire de l'Eglise, 81-83.

82. D'ALES. L'edit de Callixte, 233.

83. S. Cipriano, Epist. 10,21, PL 3, 787. Son muy instructivos los comentarios a este texto $\mathrm{y}$, en general a todo el pensamiento de $\mathbf{S}$. Cipriano de D'Ales, o.c. 240 not, 1; P. Batiffol, o.c. XXIV-XXV; B. PoschmanN, o. c. 55-57; G. RAuscheN, L'Eucharistie et la pénitence durant les six prémiers siècles, París 1910. 158s. 
y reconciliación de los adúlteros. Y son (cepiscopi» que no han llegado a romper con la Iglesia. Por ello la corriente rígida se movía dentro de la misma Iglesia y desde dentro se obstinaba en imponer ciertas limitaciones : prácticas al poder, teóricamente ilimitado, de perdonar todos los pecados. Así lo hacían los mencionados obispos en las iglesias que de ellos dependían. Sin embargo presentar como dominante a la corriente rígida sería violentar el sentido de las afirmaciones de S. Cipriano. Es más acertado pensar que, precisamente porque dominaba la tendencia benigna, un obispo - sea Agripino u otro- ha encontrado el suficiente apoyo para proponer a la iglesia de Africa como norma práctica oficial a seguir con los (moechi), la norma defendida por la tendencia benigna. Decisión que no ha podido o no se ha atrevido a tomar el Papa Calixto en la iglesia de Roma. Se ha limitado a actuar benignamente admitiéndoles a la reconciliación, que es lo que ataca Hipólito, pero sin dejar constancia escrita $o$, al menos, no consta como sobre el Edicto de Calixto.

Este predominio de la corriente benigna en Africa explica que la reacción de la corriente rígida - dirigida por un ingenio tan agudo y hábil como Tertuliano- haya sido, si no quería ceder terreno, más violenta en Africa que en Roma. Tanto los inclinados a la rigidez como los defensores de la benignidad sostienen el poder ilimitado de derecho de la Iglesia sobre el perdón de todos los pecados. En ambas comunidades eclesiales la discusión se plantea sobre la conveniencia o no de incluir dentro de la práxis pastoral el perdón del pecado de castidad. Tertuliano cree que no es conveniente perdonar de hecho dicho pecado, porque sería preparar el camino al laxismo. Pero no se para aquí. Se plantea una pregunta de mayor importancia. Admitido que la Iglesia posee poder de perdonar todos los pecados ¿quién es el sujeto de dicho poder dentro de la Iglesia? ¿La jerarquía? No. Los espirituales ${ }^{84}, \mathrm{Y}$ así comprendemos que Tertuliano se llame a sí mismo innovador y progresista frente al contenido del citado Edicto. Realmente era innovador al defender la no oportunidad de perdonar el pecado contra la castidad, cuando la mayoría de los obispos de la Iglesia africana lo perdonaban. $\mathrm{Y}$, sobre todo, era innovador por

84. Tertuliano, De pudicitia XXI, 272,8, PL 2, 1002. "Ecclesia quidem delicta donabit, sed Ecclesia spiritus per spiritualem hominem, non ecclesia numerus episcoporum". 
ese nuevo concepto determinante del sujeto del poder de perdonar los pecados.

En la Iglesia de Roma sucedía lo contrario. Creo que la corriente rígida predominaba en tiempos del Papa Calixto ${ }^{85}$. Podemos pensar que negaba la reconciliación a los culpables de faltas de castidad, puesto que Hipólito ${ }^{86}$ haciéndolo así se juzga conservador y mantenedor de la práctica de su iglesia mientras que a Calixto, que los admitía a la reconciliación, le considera innovador e introductor del laxismo ${ }^{87}$.

La discusión, a pesar de la posición diferente de las fuerzas contrarias, termina en ambas iglesias con la victoria de la opinión benigna que trata de adaptarse lo más posible a las necesidades de los fieles, conjugando los principios fundamentales de aquellos tiempos con las circunstancias concretas de cada comunidad eclesial. En ambas iglesias como consecuencia de la discusión se ha afianzado la conciencia de su poder ilimitado de perdonar todos los pecados $y$, lo que es más importante, queda confirmada su aplicación práctica. En la iglesia de Africa esta inclusión de la falta de castidad dentro de las perdonables en la praxis pastoral adquiere la fuerza de posición oficial. El paso dado por la iglesia de Roma podemos considerarlo más importante. Era más rigida, bien fuera porque hasta ese momento se desconocía el problema, bien porque, de haberse planteado antes, predominara la corriente rígida. Por eso el conceder el perdón a la falta de castidad es considerado como una innovación, mientras que en la iglesia de Africa aparece como una consolidación.

Esta impresión de mayor apertura por parte de la iglesia de Africa, en su comparación con la de Roma, queda confirmada cuando los «lapsi» planteen un nuevo problema pastoral.

85. Tertuliano, De pudicitia XII, 262, 26, PL 2 , 1002 : "neque idolatriae neque sanguini pax ab ecclesia redditu",; De pudicitia XX,272, 29 PL 2 , 1020-1023; "quaecumque ratio moecho et fornicatori pacem ecclesiasticam reddit, eadem debebit et homicidae et idololatriae poenitentibus subvenire, certe negatori et utique illi, quem in praello confessionis tormentis conluctandum saevitia deiecit" (Cfr. P. BATIFFor, o. c. XV-XVI; RausCHEN, o. c. 156 ; B. Poschmann, o.c. $46 \mathrm{~s})$.

86. S. Hipolito, Philosophoumena IX ,12, 22s.

87. Defienden que Calixto no ha innovado sino que afianza la aplicación práctica de un poder ya admitido teóricamente: P. Batrffor, o. c. XVI-XVII; 91, 96, 77, 100, 110-111; M. B. CARRA, "Le sacrement de pèitence: aperçu historique": Lumière et Vie 13 (1964) 12. 
d. El problema de los “lapsi».

Después de la consolidación de la tesis del poder ilimitado de la Iglesia de perdonar los pecados, hemos visto el nuevo avance en el que se fundamentará progresivamente la uniformidad de la praxis penitencial. Examinaremos ahora el proceso mediante el cual la praxis penitencial amplía su campo incluyendo en la lista de pecados perdonables de hecho al de apostasía. No todos están de acuerdo con esta afirmación ${ }^{88}$. Parto del supuesto, ya indicado en otro lugar, de que la norma pastoral no excluía, como orientación con valor universal, del perdón a los apóstatas. La novedad del momento pastoral, surgido de las persecuciones, está en la frecuencia y elevado número de apostasias. Ello requería una nueva adecuación a las necesidades pastorales y que se ha de enfrentar a una oposición tan fuerte que termina en el cisma. La existencia de esta oposición no puede sorprendernos después de las reacciones que se habían manifestado en la discusión sobre los (moechi), Ante todo hemos de admitir que la persecución de Decio originó una situación tan nueva en la Iglesia, que la forzó a reajustar la aplicación de sus principios en materia penitencial. La última persecución, la de Maximino, tenía como objetivo la apostasía de los jerarcas. Serían, pues más bien escasas. La persecución de Septimio Severo quedaba ya un poco distante y perdurarian los triunfos como recuerdos edificantes más bien que las defecciones. Mientras que la persecución de Decio es la primera que se extiende a toda la población cristiana, sin distinciones, enfrentándola al dilema: o heroísmo o apostasía. No extraña que entre la población causara verdaderos estragos. Esta era la situación que la Iglesia no había vivido con anterioridad ${ }^{89}$.

88. B. PoschmanN, o.c. 54: "La recherche historique se retrouve à cause de cela devant la même question que pour les troubles tertullianistes, de sorte que les mêmes opinions contradictoires s'affrontent. Ceux pour qui ce serait Callixte qui aurait, pour la première fois, ouvert la porte de l'Eglise aux adultères, font aussi faire à Cyprien et au pape Corneille un nouveau pas et accorder alors, pour la première fois, la réconciliation aux apostats, ceci sous la pression des circonstances, car autrement l'Eglise se serait dépeuplée. D'autres en revanche ne voient, dans cet usage, aucune nouveauté, mais au contraire, l'execution nette et décisive de ce que avait déjà cours sans être géneralisée". H. RoNDET, "Esquisse d'une histoire du Sacrement de pénitence": Nouvelle Reviué Théologique 80 (1958) 568. Fn ambos autores puede encontrarse una bibliografía correspondiente.

89. D'Ales, o.c. 298-301, 304-306, 311, 317; RAUSCHEN, o.c. 149-154, 1585, con su correspondiente bibliografia. 
Los escritores de la época hablan de diferentes clases de cristianos:

- Unos huyeron valiéndose de su influjo o bienes de fortuna.

- Otros sucumbieron al negarse a sacrificar a los ídolos.

- Algunos sobrevivieron a los tormentos a que fueron sometidos por negarse a sacrificar a los ídolos.

- Otros se sometieron al edicto y sacrificaron realmente a los dioses. Son los «lapsi».

- Finalmente, hubo quienes obtuvieron un certificado de haber sacrificado. aunque en realidad no lo hubieran hecho. Son los "libellati»" . También se los incluye entre los "lapsi».

Una buena parte de la población cristiana estaba complicada en un pecado que, aunque no fuera irremisible, era considerado como muy grave, y cuya conducta pastoral, a seguir con los responsables de él, aún se desconocía. La Iglesia carecía de norma práctica para la nueva situación. $Y$ junto a este nuevo elemento situacional aparece otro: el poder de los confesores. Estos encontraron, en la aparición de aquella multitud de "lapsi», el campo opropiado para lucir ese poder del que ya hablaba el Edicto de Calixto ${ }^{91}$. Los confesores eran conscientes de su prerrogativa y también lo eran los fieles que, por otra parte, veían un camino más fácil para reconciliación. En S. Cipriano leemos que los fieles acudian a los confesores "glomeratim et per multitudinem"

Pero entre los confesores unos eran admirables por su conducta en tanto que otros dejaban que desear. La disciplina penitencial parecía sustraerse a la regulación y orientación de la jerarquía. El desorden, aliado con la dolorosa situación, se dejaba sentir.

S. Cipriano adoptará una actitud verdaderamente pastoral tratando de salvaguardar lo fundamental y buscando aquello que realmente fuera más conveniente para los (lapsi». No se opone a su reconciliación. Unicamente intenta regularla. Sus escritos reflejan sentimientos paternales para con ellos. Por eso quiere que la reconciliación fructifique en una realidad íntima en los (lapsi) reconciliados y que no

90. S .Cipriano, De lapsis VII, PL 4, 471-472; Novactano, Inter Ciprian. Epist. 30, 5, PL 4, 312; "Aspice totum orbem pene vastatum, et ubique iacere deiectorum reliquias et ruinas".

91. S. Cipriano, Epist. 5, 2; PL 4, 231-5; Epist. 13, 5, PL 4, 260-261; Epist. 14, 3. PL 4, 261-164.

92. Inter Ciprian. Epist. 30, 5, PL 4, 312. 
sea una mera reconciliación externa. Entonces S. Cipriano, con clarividencia admirable, sostiene que ni el billete de los confesores ni la reconciliación otorgada por el obispo tienen valor alguno sin la penitencia y conversión internas. Si la penitencia interna era indispensable para el perdón de los pecados menores, con mayor razón debía exigirse para el perdón de los graves.

Pero hemos de reconocer, y con satisfacción, que la corriente benigna había hecho tales progresos que la Iglesia de Africa no plantea el interrogante: ¿absolver o no a los (lapsi»? o ¿la apostasía es o no pecado irremisible? La verdadera formulación de sus preocupaciones es : ¿reconciliar apresuradamente o hacerlo con prudencia? S. Cipriano entiende que no debe admitirse el apresuramiento. Reprocha a los confesores la concesión indiscriminada de los billetes de reconciliación, lo que equivale, según se trasluce a lo largo de su obra, a dispen. sarlos de la penitencia personal. S. Cipriano pretende estatuir una forma tal de conceder los billetes de reconciliación que invite a la penitencia personal, y la reconciliación sea veraz y eficiente. Al mismo tiempo apuntala un segundo elemento constante de la evolución doctrinal: la última palabra de la reconciliación procede de la jerarquía representativa de la Iglesia, del pueblo de Dios. No es que niegue todo valor a la intercesión de los confesores. Defiende que, por mucho valor que posea, dicha intercesión ordinariamente no puede dispensar del procedimiento normal: exomologesis e imposición de las manos. Reprende la conducta de aquellos que han reconciliado a los "lapsi» sin constarles de su penitencia personal y fiándose únicamente de los billetes de los (confesores) ${ }^{93}$. Subordina las prerrogativas de los con-

93. S. Cipriano, Epist. 9, 2, PL 251 252: "Nam cum in levioribus peccatis agant peccatores poenitentiam iusto tempore, et secundum disciplinae ordinem ad exomologesim veniant, et per manus impositionem episcopi et cleri ius communionis accipiant, _nunc crudo tempore persecutione adhuc perseverante, nondum restituta Ecclesiae ipsius pace, ad communionem admittuntur, et offertur nomine eorum, et nondum poenitentia acta, nondum exomologesi facta, nondum manu eius ab episcopo et clero imposita, eucharistia illis datur'

De lapsis 16, 2, PL 4, 479. "...ante expiata delicta, ante exomologesim facta, ante purgatam conscientiam sacrificio et manu sacerdotis... vis infertur corpori et sanguini Domini".

Epist. 58, 13: "...ne pulsetur ad Ecclesiam Dei, et sublata poenitentia, nec ulla exomologesi criminis facta, despectis episcopis atque calcatis, pax a presbyteris verbis fallacibus praedicetur, et, ne lapsi surgant aut foris positi ad Ecclesiam redeant, communicatio non communicantibus offertur". 
fesores a la autoridad de los obispos. Por ello se permite regular la intervención de aquéllos, pidiéndoles que expidan billetes individuales y no colectivos. Con ello tales billetes debían transformarse en testimonio del arrepentimiento interno y de una vivencia personal de la penitencia por parte de sus poseedores ${ }^{94}$. Así los confesores iniciarían una función que más tarde desempeñarán algunos sacerdotes: comprobación de la penitencia interna a través de las manifestaciones penitenciales externas.

Terminada la persecución se reúne en Concilio la Provincia de Africa. Por las cartas de S. Cipriano sabemos que se discutió sobre los argumentos bíblicos en que podría apoyarse la reconciliación o exclusión de los (lapsi). Tras un laborioso trabajo triunfó la conducta práctica deducible del principio de la misericordia y bondad de Dios ${ }^{95}$. Triunfo de la corriente benigna y presencia de la rígida a lo largo de la discusión. Tertuliano había intuido certeramente el futuro cuando escribía que el conceder la reconciliación a los (moechi) era abrir la

94. Epist, 15, 4: "Peto ut eos quos ipsi videtis, quos nostis... quorum poenitentiam satisfacuicni proximam conspicitis designetis... designetis nominatim libello et sic ad nos fidei et disciplinae congruentes litteras dirigatis".

Epist. 11, 1, PL 4, 257: "Fecerunt ad nos de quibusdam beati martyres litteras petentes examinari desideria sua. Cum pace nobis omnibus a Domino prius data ad ecclesiam regredi coeperimus, examinabuntur singula praesentibus et iudicantibus vobis".

Epist. 12, 1, P1 4,259: "Qui libellos a martyribus acceperunt et praerrogativa eorum apud Deum adiuvari possunt, si incommodo aliquo et infir mitatis periculo occupati fuerint, non expectata praesentia nostra apud presbyterum quemcumque praesentem, vel, si presbyter repertus non fuerit et urgere exitus coeperit, apud diaconum quoque exomologesim facere delicti sui possint, ut manu eis in poenitentiam imposita veniant ad Dominum cum pace quam dari martyres litteris ad nos factis desideraverunt".

95. M. B. CARRA, "Le sacrement de pénitence. Apercu historique": Lumière et Vie 13 (1964) 11: "Après mûres delibérations, éclairées par une correspondance suivie entre les deux métropoles occidentales, l'indulgence finit par prévaloir de part et de l'autre; on admit à la réconciliation ces rénegats d'un moment, non sans le soumettre à la pénitence, naturellement: pénitence sévère, soigneusement adaptée aux divers cas. Mais cette décision fut loin de contenter tout le monde. A Carthage, un parti groupé autour d'un certain Felicissime, où se remarquait surtout un prêtre, Novat, fit schisme, trouvant Cyprien trop rigide. A Rome, on avait commencé par trancher nettement en faveur de l'indulgence; puis une attitude beaucoup plus réservèe s'était fait jour, qui semble coïncider avec une certaine préponderance, au sein du college presbyteral, du prêtre Novatien. Quand enfin on put élire un nouveau pape, celui-ci, Corneille, adopta la même ligne de conduite que Cyprien. Mais Novatien, sans doute décu et vexé de n'avoir pas été porté au siège épiscopal, rompit avec 
puerta a la reconciliación de los «lapsi». Así S. Cipriano argumenta: ¿Si otorgamos la paz a los "moechi» por qué hemos de negársela a los (lapsi)? Los argumentos escriturísticos pueden aducirse tanto en favor de unos como de otros. $Y$ hasta si se tratara de los "libellati" habría que decir que son menos pecadores que los adúlteros ${ }^{96}$, El Concilio de Cartago se deja convencer y adoptará unas medidas llenas del humanismo y comprensión que vivía su cabeza pensante, S. Cipriano:

-No se reconciliará en grupos, sino que es necesario examinar cada caso concreto.

- La gravedad del pecado de apostasía aconseja no reconciliar apresuradamente; pero seria un error privarles de toda esperanza de reconciliación.

- Los «libellati» pueden ser reconciliados una vez estudiado individualmente la situación de cada uno y después de una penitencia adecuada. A los (sacrificati) se les retardará la reconciliación hasta la hora de la muerte y supuesto que antes hayan hecho penitencia.

- Los "lapsi» que no quisieran practicar la penitencia durante su vida, no serán reconciliados ni a la hora de la muerte.

-Y es curioso, anota Batiffol, que no se haga mención alguna de las prerrogativas de los "confesores" y hasta que implícitamente se nieguen ${ }^{97}$.

Queda confirmado que la iglesia de Africa estaba dirigida casi totalmente por la corriente benigna. El aplazamiento de la reconciliación de los "sacrificati» hasta la hora de la muerte puede ser una huella ligera de la tendencia rígida. Pero tan tenue es su influjo que el Concilio se ve precisado a regular la desviación de la benignidad en cuanto que condujera a la reconciliación indiscriminada.

Corneille entrainant avec lui un groupe important qui s'offusquait d'une indulgence taxée de faiblesse scandaleuse. Organisée en Eglise schismatique autour de Novatien consacré évêque et dressé contre le pape légitime, ces gens donnèrent assez étrangement la main aux partisans de Novat: confondus sous le nom commun de Novatiens ou Novatianistes, ils mantiendront pendant plusieurs siècles leur opposition au nom d'un idéal de pureté intransigeante" (Cfr. E. AMANN, Novatiens; D .T. C. XI, 829; ID., Pénitence: D. T. C. XII 773).

96. S. CIPRIANO, Epist. 55,20: "Nam et moechis a nobis poenitentiae tempus conceditur. Multo et gravior et peior moechi quam libellatici causa".

97. Cfr. P. BATIFFOL, o. c. 127-128. 
Veamos ahora cómo pensaba la Iglesia de Roma, en la que habíamos indicado - en cuanto a los (moechi) - dominaba la corriente rígida. Ahora también es más remisa en tomar conciencia de este nuevo problema. La mentalidad que matiza los primeros planteamientos del mismo se entrevé en las respuestas a las cartas recibidas de $\mathrm{S}$. Cipriano. Es imposible descubrir la convicción sobre las prerrogativas de los "confesores», que fue una de las causas impulsoras hacia la benignidad en la iglesia de Africa. La carta respuesta a S. Cipriano, que se atribuye a Novaciano, trasluce cierta benignidad al mismo tiempo que rezuma rigorismo, aunque sin llegar en lo tocante a los (lapsin a aquella intransigencia que Tertuliano manifestó frente a los "moechi». Algunos historiadores creen encontrar en ellas los datos suficientes para afirmar que Novaciano veía la continuidad de la tradición y de la fe en la severidad ${ }^{98}$. De hecho $S$. Cipriano se lamenta de la crueldad que supondría decir a uno: laméntate, gime día y noche, pero después de tanta expiación morirás sin obtener la reconciliación con la Iglesia. Y, aunque no podemos comprobar la certeza de la opinión, el autor anónimo del tratado Ad Novatianum le reprocha el negar toda reconciliación a los (lapsi) ${ }^{29}$.

Elegido el Papa Cornelio también la iglesia de Roma se reúne en Concilio con una considerable participación de obispos, sacerdotes y diáconos. Poco sabemos sobre este Concilio. Unicamente Eusebio nos dice que Novaciano fue expulsado de la Iglesia con aquellos que aceptaban y seguían su opinión inhumana. Y S. Cipriano afirma que

98. En la contestación enviada a $\mathbf{S}$. Cipriano y a todos los obispos por Novaciano se lee: "Absit ab ecclesia Romana vigorem suum tam profana facilitate dimittere, et nervos severitatis eversa fidei maiestate dissolvere, ut... properata nimis remedia communicationum utique non profutura praestentur" (PL 3,966). "Oremus ut cecidisse referuntur, delicti sui magnitudinem agnoscentes, intellegant non momentaneam neque praepoperam desiderare medicinam... Pulsent sane fores, sed non utique confringant. Adeant ad limen Ecclesiae, sed non utique transiliant" (PL 3, 968-969).

E igualmente pensaban los "martires" de la iglesia de Roma: "Dum ad episcopum illos remittunt... consulendum putaverunt; et dum illis non ipsi communicant, evangelicae legis illibatam sinceritatem custodiendam iudicaverunt" (Epist. 36,2). Novaciano anota": ...severitatem evangelicae disciplinae protulerunt et illicitas petitiones ab Ecclesiae pudore revocarunt" (PL 3,967).

99. S. CIPRIANO, Epist. 30, 2,4 y 6:Ad Novatianum 12, PL 3, 1213 4: "Novatiane, nullam spem pacis ac misericordiae habere lapsos praedicas": :"...quod poenitentia lapsorum vana nec possit eis proficere ad salutem". cfr. EUSEBIO, Historia Eclesiástica VI, 43,1 . 
se tomaron, más o menos, las mismas precauciones y decisiones que en el de Cartago. Intencionadamente subraya esta prioridad temporal de las decisiones tomadas por el Concilio de Cartago. Eran decisiones literalmente iguales, pero con significado contrario. Cartago trataba de reprimir la indulgencia incondicionada y tumultuaria de los "confeso. res", mientras que Roma se proponía reducir el rigorismo intransigente de los novacianos ${ }^{100}$. Porque este rigorismo que, antes de tomar sus decisiones los Concilios de Cartago y de Roma, solamente se vislumbraba, una vez tomadas, se exterioriza abierta y claramente.

No ignoro que algunos historiadores tratan de presentar el cisma de Novaciano como una cuestión de tipo personal al no ser elegido Papa, como parecía esperar ${ }^{101}$. Lo cierto es que, desde el punto de vista doctrinal aunque sólo fuera por buscar un apoyo racional, protestan contra la reconciliación de los (lapsi». Precisamente S. Cipriano les acusará de ilógicos ya que, protestando de la reconciliación de los (lapsi», mantienen a su alrededor a personas - creen que se refería a Novato- de moralidad bastante sospechosa. No podemos olvidar, finalmente, que cesta unanimidad de la condena de Novaciano no se obtuvo sin dudas ni defecciones) ni que "si bien es cierto que el cisma de Novaciano se apoyaba en un hecho personal, ello no nos impide reconocer también en todo esté asunto el eterno conflicto entre la moral rigorista y la moral benignas ${ }^{102}$.

100. S. CIPRIANO, Epist. 55,6: "Super hac re scripsimus ad Cornelium collegam nostrum, qui et ipsi cum plurimis coepiscopis habito concilio in eamdem nobiscum sententiam pari gravitate et salubri moderatione consensit".

$Y$ sobre Novaciano leemos en S. CIPRIANO, Epist. 58,2: "Novatiano nuper retuso et refutato et per totum orbem a sacerdotibus Dei abstento".

101. B. POSCHMANN, o. c. 57: "Ce n'est pas chez Cyprien que se trouve la nouveauté mais plútot chez son adversaire Novatien. Lui aussi, comme nous l'avons vu, était, au début de la pérsecution, opposé seulement à la réconciliation inconsidérée des "lapsi", mais non à la réconciliation en elle-même. Pour la réintégration des mourants avant pénitence complète, il inspira même Cyprien. Lorsqu'il protesta plus tard contre la décision conciliaire confirmant cette attitude, ce fut un véritable reniement de son ancien point de vue. C'est sa doctrine pénitentielle qui dut se prêter à justifier son entrée en scène comme anti-pape, c'est-à-dire le schisme".

102. P. BATIFFOL, o. c. 135: "Cette sentence unique avait eu deux effets opposés, à Carthage de supprimer l'indulgence inconditionnée et tumultuaire des martiyrs, à Rome de réduire le rigorisme intransigeant des Novatiens. Mais, des deux côtés ensemble, c'était en définitive la discipline consacrée par Calliste qui triomphait. Une fois de plus le traitement des pécheurs se tempérait de miséricorde". 
Era una conquista más de la moral de la benignidad y también una constatación de que todo este hacer el camino se ha logrado en medio de la oposición, que se ha manifestado bien antes bien después de haber tomado las decisiones benignas. Fueron numerosos los que se opusieron a la reconciliación de los «lapsi» y su influjo persistía du. rante algunos siglos.

\section{Supervivencia de aMbas CORRIENTES}

EN LA HISTORIA POSTERIOR.

La persistencia de ambas tendencias se hace sentir en los siglos posteriores en dos formas concretas:

I. En la reviviscencia de las dudas cada vez que, por unas razones u otras, vuelve a reclamar la atención alguno de los problemas anteriormente solucionados, especialmente, los (moechi» y los (lapsi).

2. Y en las soluciones dadas a las dificultades que surgen por primera vez.

Sería interesante conocer el por qué se plantea en el siglo IV el problema de los apóstatas. En ocasiones se alude a aquellos que, o porque han caído en cautiverio o porque han convivido con los paganos, han apostatado. Lo cierto es que el siglo IV vuelve a vivir cierta preocupación por el problema de los apóstatas y los concilios sienten la necesidad de establecer normas de conducta práctica en lo referente a su reconciliación. El canon 75 del Concilio de Elvira -305prescribe que no se diera la comunión (nec in finem) a aquellos que hubieran caído en la idolatría siendo ya adultos ${ }^{103}$.

103. "Qui post fidem baptismi salutaris adulta aetate ad templum idoli idolatraturus accesserit, et fecerit quod est crimen capitale quia est summi sceleris, placuit nec in finem eum communionem accipere" (cfr. BRUNS, Canones II, 2).

104. "De his qui falso accusant fratres suos, placuit eos usque ad exitum non communicare" (cfr. BRUNS, Canones II, 109). "De his qui apostatant et nunquam se ad ecclesiam representant, ne quidem poenitentiam agere quaerunt, et postea infirmitate arrepti petunt communionem, placuit eis non dandam communionem nisi revaluerint et egerint dignos fructus poenitentiae" (BRUNS, o.c. 110).

"Qui acta paenitentia,... et militiae cingulum, et ludicras voluptates, et nova coniugia, et inhibitos denuo appetiere concubitus,... quia iam non habent suffugium paenitendi,... sola intra ecclesiam fidelibus oratione 
Pocos años más tarde el canon 14 del Concilio de Arlés -314excluye de la comunión (usque ad obitum) a dos clases de pecadores:

a.- a quienes denuncian falsamente - cualquier falsa denuncia, verse o no sobre la herejía- a alguno de los hermanos.

b. A los apóstatas o aquellos que, habiendo practicado la forma oficial de penitencia, recaían en alguno de los pecados a ella sometibles ${ }^{104}$.

Algunos pretenden englobar bajo una sola interpretación a ambos concilios. Aún quienes defienden interpretaciones distintas según que se trate de uno u otro Concilio, admiten que el c. I4 de Arlés es el correlativo del c. 75 de Elvira. En cuyo caso parece que a los apóstatas habría que negarles la comunión con la Iglesia aún al fin de la vida. No existen pruebas apodícticas de que se considerara irremisible el pecado de apostasía o de recaída, pero parece cierto que a tales pecadores se les negaba el signo externo de la reconciliación con el pueblo cristiano. Esta interpretación sería una prueba clara de que el rigorismo persistía. Sin embargo otros autores opinan que se ha de hacer una interpretación más benigna de los cánones de ambos concilios ${ }^{105}$. En cualquiera de los casos ambos cánones traslucen cierto rigor puesto que aplazan la reconciliación hasta el final de la vida, aún cuando en el transcurso de la misma se hayan entregado sinceramente a la práctica de la penitencia personal. Quienes no hayan ejercitado esta penitencia personal no pueden soñar con la reconciliación ni siquiera al final de la vida.

Vogel ve en la solución del Concilio de Arlés una continuidad progresiva de la tomada por S. Cipriano ${ }^{100}$. Pero no. Encierra mayor

iungantur, sacrae mysteriorum celebritati quamvis non mereantur intersint, a dominicae autem mensae convivio segregentur,... quos tamen, cum ad Dominicum coeperint proficisci, per communionis gratiam volumus sublevari" (cfr. JAFFE, n. ${ }^{\circ}$ 255).

El papa Siricio escribe al obispo de Tarragona el 10 de febrero del 385 : "Sed postquam Dominus noster pacem ecclesiis suis reddidit iam, depulso terrore, communionem dare abeuntibus placuit, ne Novatiani haeretici, negantis ventam asperitatem et duritiam subsequi videamur" (Epist. 1, PL 13, 1131-1147).

105. S. G. RIVAS, La penitencia en la primitiva iglesia española. Estudio histórico dogmático $\overline{\mathrm{y}}$ canónico de la penitencia en la Iglesia española etc. Salamanca 1950.

106. C. VOGEL, La discipline pénitentielle en Gaule. Des origines a la fin du VII siècle, París 1952,23. Es curioso que este autor ordinariamente 
benignidad la actitud de $S$. Cipriano. En primer lugar, S. Cipriano distinguía entre "libellati» y (sacrificati», lo cual no hace en forma equivalente el Concilio de Arlés. Tal vez no hubiera lugar a esa dis. tinción exacta y literal, pero sí que podría encontrarse su correspondiente equivalencia. $\mathrm{Y}$ así se hará en años posteriores. En segundo lugar, en S. Cipriano encontramos un gran humanismo, adaptado a toda posible circunstancia posterior: en el caso de que se temiera una nueva persecución, sería conveniente reconciliar aún a los "sacrificati) arrepentidos para dotarles de las fuerzas requeridas por la situación. Y hemos recordado que juzga inhumana y desesperante la actitud de quienes los invitaban a hacer penitencia día y noche pero les cerraban toda esperanza de reconciliación aún al final de la vida. Hay, pues, razones para dudar de que estos cánones expresen un progreso de la benignidad. Pocos años después el magnífico canon 13 del Concilio de Nicea 325- significa una mitigación relativa a la conducta a seguir con los «lapsi). Recomienda que se conceda el viático en sentido propio ${ }^{107}$ a todos los moribundos sin excepción alguna. Luego, también a los "lapsi» sin condicionarlo a que hayan practicado o no la penitencia durante su vida. La decisión de Nicea es conocida en Francia y el c. 3 del Concilio de Valencia ordena que se otorgue el viático a cuantos hayan practicado algo de penitencia a lo largo de su vida, y se niega a quienes no la hayan practicado ${ }^{108}$. Tal insistencia de los concilios en una solución que parecía ya adquirida, hace pensar que existía una cierta oposición en el episcopado o, al menos, en algunos obispos católicos.

Otra prueba más de la supervivencia e influjo de la corriente rígida podemos deducirla del hecho de que algunos obispos quedan tan insatisfechos con las soluciones conciliares tendentes a la benignidad que se arriesgan a consultar expresamente a Roma sobre casos ya so-

exteriorice su tendencia a probar la benignidad de la iglesia de Francia hasta con ciertos riesgos de no ser objetivo.

107. Cfr. BRUNS, Canones II, 18.

108. "Círca vero personas qui se post unum et sanctum lavacrum vel profanis sacrificiis daemonum, vel incesta lavatione polluerint, eam censurae formam duximus esse servandam, ut his iuxta synodum nicaenam, satisfactionis quidem aditus non negetur, ne infelicibus lacrimis vel solatii ianua desperatione claudatur, acturi vero paenitentiam usque in diem mortis, non sine spe tamen remissionis, quam ab eo plane sperare debebunt, qui eius largitatem et solus obtinet et tam dives misericordia est, ut nemo desperet" (BRUNS, o. c. II, 112). 
lucionados por los concilios. Así el Papa Siricio confirma las soluciones conciliares en su contestación a las preguntas planteadas por $\mathrm{Hi}$. merio de Tarragona en el $385^{109}$.

La prueba definitiva de que la mentalidad reflejada en las preguntas de Himerio de Tarragona es una reminiscencia de la corriente rígida nos la facilitan los pasos que van dándose en cuanto a los moribundos. Si morían mientras estaban realizando las adecuadas obras penitenciales, se les concedía una reconciliación que pudiéramos llamar provisional. S. León I recuerda, en el 452, a Teodoro de Frejus que, al actuar así, sigue una conducta distinta de la practicada en la iglesia de Roma. Ello significa que en Roma se les concedía la reconciliación que los franceses llamaban «absolutísima» ${ }^{110}$. Parece, pues, que, comparando unas iglesias con otras, podría hablarse de una doble reconciliación según los efectos que se les asignara.

También se replantea en diversas ocasiones el tema de la castidad, siguiendo una evolución bastante similar a la indicada en cuanto a los apóstatas y reincidentes ${ }^{111}$.

Al final de este hacerse, en medio de la discusión de los primeros siglos, encontramos como posiciones firmes las siguientes:

r. Que la Iglesia tiene poder de derecho de perdonar todos los pecados.

2. Que su aplicación o limitación práctica quedan confiadas a la prudencia eclesial.

109. PL. 56, 556.

"La lettre de Sirice, si elle a été connue en Gaule, cas fort probable, mais non certain, n'a donc pas, apparemment dissipé toutes les inquietudes" (C. VOGEL, La discipline pénitentielle en Gaule. Des origines a la fin $d u$ VII siècle, Paris 1952, 39). "Si parfois les canons conciliaires galo-romains font eco aux directives venues de Rome, il est de cas où une certaine résistance de l'épiscopat se laisse deviner et où se fait jour une manière d'agir différente de celle proposée dans les rescripts pontificaux" (C. VOGEL, o. c. 30).

110. C. VOGEL, o.c. 36-37.

111. "De puellis vero quae se Deo voverunt, si ad terrenas nuptias sponte transierint, id custodiendum esse decrevimus, ut poenitentia his nec statim detur; et cun data fuerit, nisi plene satisfecerint Deo, in quantum ratio poposcerit, earumdem communio differatur" (Conc. de Valence deI 374 c. 2, cir. BRUNS, Canones II, 112).

Himerio de Tarragona en su consulta al papa Siricio trata también de aquellas religiosas que, permaneciendo en el monasterio, violan el voto de castidad. PL 56, 557. 
3. Que en todos los casos concretos de ampliación examinados se ha juzgado conveniente hacerlo por estimar que así lo aconsejaba la salud espiritual de personas bien dispuestas pero débiles ante las dificultades presentadas por las circunstancias históricas.

4. Todo esto, unido a la profunda conciencia del compromiso personal que el penitente adquiría con Dios y su Iglesia, llegó a cuajar en una forma penitencial oficial de duras exigencias, que comúnmente se resumen asi :

- penitencia pública

- penitencia dramática

- penitencia laboriosa

- penitencia no iterable

- penitencia excepcional por doble razón. Primeramente porque. dada su dureza serían pocos los pecados que en los primeros siglos habría que someter a la penitencia. Suelen señalarse: adulterio, apostasía y homicidio. Excepcional, en segundo lugar, por las consecuencias que acarreaba el formar parte del cordo poenitentium\%. El penitente quedaba marcado desfavorablemente en la opinión de los demás; debía abstenerse de todo uso matrimonial si estaba casado, o de contraer matrimonio si era soltero; le quedaba prohibido el uso de las armas, aunque perteneciera al ejército; no podía dedicarse a los negocios; quedaba excluido del acceso a las órdenes sagradas y finalmente se aconsejaba que no se admitiera a los jóvenes a la práctica de la penitencia oficial ${ }^{112}$.

\section{PERIODO DE PREPÄRACION PARA EL PASO A LA TARIFADA}

En los siglos posteriores la reflexión desplaza su atención a las

S. León se ocupa de estos problemas en sus cartas 159 , PL 54, 1135-1140 y 167 , PL 54, 1199-1209.

112. La bibliografía y textos comprobantes, ya los aduje en articulos anteriores, Z. HERRERO, "Anotaciones sobre la evolución de las formas de penitencia con las que se exteriorizaba el perdón de los pecados": $X X X$ Semana Española de Teologia, Madrid 1972, 223-250; ID., "La penitencia y sus formas. Examen de su evolución histórica": Estudio Agustiniano 6 (1971) $3-31 ; 7$ (1972) $37-71$. 
exigencias de la penitencia oficial, cuyo desajuste e inadaptación vır ven los cristianos tanto más profundamente cuanto más se alejan temporalmente de los siglos en los que se elaboró la forma penitencial antigua. Pesa la necesidad de aligerar tanto las exigencias pre-penitenciales como las postpenitenciales. También fue tarea difícil y sólo realizada a medida que surgían las necesidades.

En un primer estadio, que abarca dos o tres siglos el esfuerzo renovador mantiene un hondo respeto hacia la no-iterabilidad de la penitencia. Se limita a la mitigación:

I. de las obligaciones adherentes a la permanencia en el cordo poenitentium), concretando su acción en un aligerar las otras exigencias de la forma penitencial antigua.

\section{a. Duración:}

Es larga, aunque no puede precisarse con exactitud en cuanto a la Iglesia Occidental. Algo más se puede concretar en cuanto a la Oriental. S. Basilio habla de 7 años en cuanto a la fornicación y de 20 años si se tratara del homicidio. Durante estos años los penitentes recorrían distintas vivencias penitenciales como graduadas según se aproximaban a la reconciliación. Hubo momentos en los que la lglesia Occidental intenta trasladar a su territorio esta organización, pero no cuaja y finalmente hasta se prohibe ${ }^{n 1}$. De todas formas se piensa que hasta el siglo IV se permanecía varios años en el «ordo poenitentium». A partir del siglo IV se acorta sensiblemente y todos son reconciliados en Pascua; más tarde limitan la preparación al tiempo de cuaresma; después se intensificará sobre todo desde el miércoles santos hasta el jueves o viernes santo y con los moribundos se llega a la máxima mitigación ${ }^{114}$.

113. SOZOMENE, Histoire ecclesiastique, VII, 86; D. T. C. XII, 797,832, cfr. H. RONDET, "Esquise d'une histoire du sacrement de Pénitence". Nouvelle Revue Theologique 80 (1958) 570-571; A. BOUDINHON, "Sur l'histoire de la pénitence. A propos d'une ouvrage récent": Revue d'Histoire et Litterature Religieuses 2 (1897) 327; E. VACCANDARD, "Le pouvoir des clefs et la confession sacramentelle. A propos d'une ouvrage récent": $R e-$ vue du Clergé Francaise 14 (1898) 199-202, 205; FELIX III Epist. 7, PL 58, 925.

114. S, LEON, cfr. JAFFE, n. ${ }^{\circ} 311$.

"Qui sive ex gravioribus commissis sive ex levioribus paenitentiam ge- 


\section{b. Exigencias del tiempo preparatorio:}

También éstas se hacen paulatinamente más llevaderas. Los que recaían en pecado todavía eran apartados de la comunidad eclesial, pero ya se les admitía a la oración en común con los fieles, a la celebración de los misterios, excepto a la comunión, y al viático en el lecho de muerte como parece desprenderse de la intervención del papa Félix ${ }^{115}$. Finalmente queda suprimida la exclusión externa de la comunidad eclesial ${ }^{116}$.

Es muy probable que las mitigaciones en cuanto a la duración y exigencias del (ordo poenitentium) acusaran el influjo de otros dos elementos de la praxis pastoral. Uno de ellos era ese matiz peyorativo, casi infamante, de la penitencia en su forma antigua y dentro de la mentalidad de aquella época. He recordado las prohibiciones de recibir las órdenes sagradas a los que habían practicado la penitencia oficial e igualmente los clérigos, ya ordenados, no podían formar parte del "ordo poenitentium" para obtener la remisión de sus pecados. Se idearán otras formas apropiadas para ellos. Tanto es así que, en algún caso, el interesado pide ser admitido a la penitencia pública para impedir su promoción al episcopado ${ }^{117}$.

Más con el tiempo y a medida que la gran masa de cristianos se alejaba y aplazaba la recepción de la penitencia oficial hasta el final de su vida, se fueron haciendo notar aquellos que la practicaban por la integridad de sus costumbres y con miras a su perfección. Llevaban una vida austera que los distinguía muy poco de los confesores. Estos son los que contribuyeron con su vida ejemplar a liberar a la penitencia oficial de aquel matiz peyorativo y casi difamante. El cor-

runt, si nulla interveniat aegritudo, quinta feria ante Pascha eis remittendum romanae ecclesiae consuetudo demonstrat".

INNOC. I ad Decentium Eugubinum, Epist. 25, 10, PL 20, 551: "Si quis in aegritudinem, inciderint, atque usque ad desperationem devenerit, eis est ante tempus Paschae relaxandum, ne de saeculo absque communione discedat".

115. FELIX III, Epist. 7, PL 58, 925.

116. E. VACCANDARD, a.c. 206-207.

117. En artículos anteriores quedaron convenientemente indicados los textos correspondientes. "...et dès la fin du IV siècle, on vit des pieux personnages s'accuser de crimes et demander la pénitence pour éviter d'être ordonnés évêques". (A. BOUDINHON, a.c. 344 ; Conc. Valent. a. 374, y la carta del Concilio al Clero y a la iglesia de Fréjus. 
do poenitentium) comenzaba a ser considerado como algo meritorio y digno de elogio. Podían gloriarse de haber practicado la penitencia. De aquí que los obispos fueran propensos a elegir a sus clérigos de entre los penitentes a pesar de las frecuentes prohibiciones que encontramos en los siglos V. y VI. Naturalmente se comenzó admitiéndolés a las órdenes menores, para admitirlos después también a las mayores ${ }^{118}$.

2. de las obligaciones postpenitenciales.

También aquí podemos señalar brevemente algunas mitigaciones. Es significativo que entre otras cuestiones Rústico plantee al papa. León las siguientes: ¿puede autorizarse a los que han hecho la penitencia a entregarse a los negocios, a convertir el servicio de las armas en ocupación de su vida, a casarse? El papa en su contestación mantiene firme la prohibición de las armas, mientras simplemente desaconseja el entregarse a los negocios prohibiendo la defensa de los propios intereses ante los tribunales. Se deroga la imposición de la castidad total después de haber practicado la penitencia oficial, al menos como norma universal. Los jóvenes que, a las puertas de la muerte recibieron la reconciliación pueden contraer matrimonio o vivir conyugalmente en el contraído con anterioridad para evitar la incontinencia ${ }^{119}$.

En todos estos casos predomina el sentido de soluciones excepcionales. Las mitigaciones permanentes establecidas dentro del periodo dominado por la forma antigua de penitencia oficial son las establecidas por las prácticas de reconciliarse, no oficiales y coexistentes con la forma oficial, sobre todo durante la época inmediatamente anterior a la penitencia tarifada. En otro artículo he hablado de estas formas: la "(professio religiosa), la (satisfatio secreta) y el "(agère poenitentiam) ${ }^{120}$.

118. A. BOUDINHON, a.c. 343-344; C. VOGEL, La discipline pénitentielle en Gaule. Des origines a la fin du VII siècle, Paris 1952 donde pueden encontrarse numerosas decisiones de los concilios de la iglesia de Francia a este respecto. 1209).

119. Carta de S. León a Rústico de Narbona (Epist. 37, PL 54, 1199-

120. La bibliografía correspondiente y anotaciones al pensamiento de S. Cesáreo de Arlés quedó indicado ya en el artículo "La penitencia y sus formas. Examen de su evolución histórica": Estudio Agustiniano 6 (1971) 3-31. 
Encierran una graduación progresiva en la eliminación de los elementos que hacían impracticable la forma oficial, culminando en el (agere poenitentiam» que prácticamente anula todas las graves obligaciones de la forma oficial, a excepción de la no interabilidad de la misma. La preocupación pastoral y laboriosa de S. Cesáreo de Arlés, para asentar una justificación racional en el orden de los principios y para lograr la aceptación en el terreno práctico del "agere poenitentiam), nos permite conocer mejor el aspecto de conquista lenta, litigiosa y en medio de la oposición de todas estas mitigaciones.

Nacimiento de la penitencia «tarifada».

En relación con la penitencia antigua representa la mitigación más importante. Por ello convienen los estudiosos en que significa un nuevo período en la elaboración de las formas penitenciales. Las formas extraoficiales anteriores han procurado, en medio de todas las mitigaciones que introducían, mantener como sagrado el principio de la no iterabilidad de la forma oficial. La tarifada, por el contrario, no sólo discute sino que suprime radicalmente la no-iterabilidad de la forma oficial de penitencia. Con la posibilidad de recibir el perdón cuantas veces fuere necesario y el penitente esté preparado se crea una nueva forma penitencial, en principio extraoficial y hasta condenada como (execrabilis" por el Concilio de Toledo ${ }^{12 i}$, pero que con el tiempo conquistará la categoría de forma oficial.

Ciertamente el cambio fundamental está en la iterabilidad, pero su influjo se deja sentir abiertamente en otros campos como en el del ministro de la penitencia. Ya no va a serlo de forma ordinaria el obispo. Lo serán también los presbíteros.

M̄ayor aún será su repercusión sobre el método de configuración de la forma penitencial. En la penitencia pública antigua se partía, fundamentalmente, de ciertos principios como el de la no iterabilidad - por su comparación con el bautismo-y el de la imposibilidad de la recaída si es que el pecador se había arrepentido de verdad la primera vez que recibió el perdón. Las necesidades pastorales durante varios siglos habían logrado considerables mitigaciones en otros as-

121. Concilium Toletanum (a. 589) c. XI cit. por A. BOUDINHON, "Sur l'histoire de la pénitence. A propos d'une ouvrage récent": Revue d'Histoire et Littérature Religeuses 2 (1897) 502. 
pectos, pero admitían reverencialmente y contenían su voz ante los principios de la no-iterabilidad e imposibilidad de recaída en los graves pecados sometibles a la penitencia pública. Con la nueva forma de la penitencia tarifada, que ha surgido no talmente como fruto de la reflexión pura sino al contacto con las necesidades pastorales, éstas adquieren una mayor importancia en su configuración. No es que conquisten la categoría de ser el punto de referencia de la nueva elaboración, pero sí que entran en conjugación con los principios condicionando ciertas conclusiones hasta ahora aceptadas pacíficamente y hasta haciendo claridad en la interpretación y alcance de los principios teóricos. Este aspecto del influjo de las causas pastorales pienso acentuarlo convenientemente en un próximo artículo. Ahora solamente quisiera señalar que la penitencia tarifada, que con su mitigación suponía el nacimiento de una nueva etapa en la evolución de las formas penitenciales, será víctima de la misma ley de la historia - evolución hacia la benignidad- que la había hecho triunfar. Sufrirá una serie de mitigaciones hasta desembocar en lo que los estudiosos consideran el tercer período de las formas penitenciales: la elaboración teológica de los siglos XII-XIII, sancionada después por el Concilio de Trento.

Y es que la penitencia tarifada como sucesora inmediata de la forma penitencial antigua arrastra todavía un fuerte sentido vindicativo y satisfactorio mediante las obras penitenciales. Dos aspectos estimularán sensiblemente a una mayor adaptación : I) las penitencias impuestas por los pecados no abarcan un campo tan amplio de la vida cotidiana como el comprendido por las exigencias postpenitenciales de la penitencia antigua, pero sí que duran largos años $y$, a veces, toda la vida; y 2) el no recibir la absolución ni admitir a la comunión hasta que no se hubieran cumplido dichas penitencias, a no ser que se tratara de casos excepcionales.

En cuanto al primer punto recordemos que los pecados menos importantes tenían como penitencia tres, cinco, diez o veinte días de ayuno, mientras que las transgresiones más graves oscilaban entre uno y veinte años de penitencia y hasta toda la vida. Así por cada pecado. Entonces sumemos los años merecidos por cada pecado y nos encontraremos en el balance final con un número tal de años que exceda al de una vida ordinaria. 
Era nâtural que también la penitencia tarifada se encarrilara pronto por la vía de las reformas. A ello contribuyen diversas causas :

a. - la situación de los moribundos con quienes se tiende a reducir lo más posible sus exigencias.

b. - el hecho de que las diversas familias penitenciales no coincidían en las penitencias que asignaban a cada pecado, siendo unos más benignos que otros.

c. - la acumulación de una cantidad increible de años de pentencia sobre el pecador que habia incurrido en varios y graves pecados, exigía establecer ciertas equivalencias, si querían impepedir que el penitente cayera en el desaliento. Estas equivalencias consistían en suplir la cantidad de años y obras penitenciales con un menor número de años y obras penitenciales pero más intensas, como las (triduanae).

Primeramente las equivalencias y redenciones quedaban restringidas a los casos de necesidad bien por enfermedad que le impedían los ayunos prolongados o bien por proximidad de la muerte. En estos casos podría redimir sus prolongados años de ayuno penitencial mediante obras de misericordia, donaciones a la Iglesia o a los pobres, etc. Además en este primer período de las (redenciones) quedaba sometido al obispo o sacerdote si había lugar o no ella y concretamente cúal debía escoger.

Posteriormente se daban a conocer distintas equivalencias de penitencias en los mismos penitenciales y entre ellas escogía libremente el penitente mismo sin intervención del ministro de la penitencia ${ }^{122}$.

122. Todos y cada uno de los puntos indicados en el texto pueden comprobarse en las obras especializadas en el estudio de los penitenciales, limitándome a indicar dos obras fundamentales: F. W. H. WASERSCHLEBEN, Die Bussordnungen der abendländische Kirche nebs einer rechtsgeschichlichen Einleitung, Halle 1851; H. J. SCHMITZ. Die Bussbücher und die Bussdisziplin der Kirche nach handschriftlichen Quellen dargestellt, Düsseldorf 1958. También quiero recordar un interesante artículo "Zur Geschichte der Pönitentialbücher": Archiv für Katholische Theologie 30 (1873) 204-227.

\section{Z. Herrero.}

\section{(Continuará).}

